\title{
Health Effects of Patients Given Methoxyflurane in the Pre-Hospital Setting: A Data Linkage Study
}

\author{
Ian G. Jacobs*
}

Discipline of Emergency Medicine (M516), University of Western Australia, 35 Stirling Hwy, Crawley 6009, Australia

\begin{abstract}
Background: Methoxyflurane administered via an inhaler is a common analgesic agent used by ambulance services in Australia; however little published data exists as to its efficacy or effectiveness in this setting. There have been several reports that have suggested that the use of Methoxyflurane may be associated with the occurrence of hepatitis and renal disease. Such concerns have led to an increasing reluctance to use Methoxyflurane as an analgesic agent in the prehospital setting. The aim of this study was to determine whether the event rates of heart disease, renal disease, hepatic disease, diabetes or cancer in patients who received Methoxyflurane compared with those not receiving Methoxyflurane prehospital.

Methods: Routinely collected administrative data for ambulance, emergency department, hospital morbidity and mortality were linked by using probabilistic matching to establish a cohort of patients managed by the ambulance service in Western Australia. The cohort covered a period of 10 years $(1990$ - 2000) with follow-up until 2004 allowing for a minimum of four and maximum of 14 years follow-up. Primary outcome was defined as a composite end point of any record indicating either hospital admission or death for the diseases under investigation. Event rates were age standardised and odd ratios plus $95 \%$ confidence intervals were to determine risk estimates.

Results: Total 135,770 patients were entered into the study of which 17, 629 (13\%) had received Methoxyflurane. There were $14,410(81.7 \%)$ patients, where Methoxyflurane was administered only once with one patient receiving Methoxyflurane on 27 occasions. Trauma was the most common indication for Methoxyflurane being administered to 9, 755 (55.3\%) patients. The odd ratios for each of the five disease groups under investigation ranged from 0.87 to 1.06 with the $95 \%$ confidence interval for each estimate including 1.0.

Conclusion: There was no difference observed in event rates for heart disease, renal disease, hepatic disease, diabetes or cancer in patients who received Methoxyflurane in the pre-hospital setting as compared with those not receiving Methoxyflurane.
\end{abstract}

Keywords: Methoxyflurane, Analgesia, Emergency Medical Service, Record Linkage.

\section{INTRODUCTION}

Published reports of Methoxyflurane dating back to the 1960 's identify its use initially as an anaesthetic agent than more recently as a analgesic for use in the pre-hospital setting [1-6]. While Methoxyflurane - a halogenated ether - has been used as an analgesic by numerous ambulance services in Australia for over two decades, very few clinical data describing its efficacy, effectiveness and safety currently exists. Recent Australian studies have demonstrated that in children, Methoxyflurane appears to be an effective analgesic with a very low side effect profile $[7,8]$.

In the late 1980s, there were a number of published reports indicating that the use of Methoxyflurane may potentially be associated with harm [9-13]. This harm was mainly observed when Methoxyflurane was used in obstetrics, where elevated inorganic fluoride levels in mothers and attending staff. In 1983, Delia identified two cases of hepatitis associated with Methoxyflurane when used for obstetric

*Address correspondence to this author at the Discipline of Emergency Medicine (M516), University of Western Australia, 35 Stirling Hwy, Crawley 6009, Australia; Tel: +61 418916261; Fax: +61 89346 1665; E-mail: Ian.Jacobs@uwa.edu.au analgesia [10]. More specifically in 1987, Toomath described two cases of renal failure leading to death following administration of Methoxyflurane over a period of 14 and 16 days [9]. Methoxyflurane was subsequently withdrawn in New Zealand. While the clinical and anecdotal evidence would indicate that Methoxyflurane is a useful and effective analgesic agent; its potential renal and hepatic toxicity in particular continue to raise concerns in regards to safety.

The Western Australian Ambulance Service (WAAS) is responsible for providing the ambulance service in the Western Australia and has been using Methoxyflurane as its primary analgesic agent for over two decades. Despite such extensive use, an evaluation of any potential health effects on patients administered Methoxyflurane as a pre-hospital analgesic has not been undertaken.

The Western Australia has considerable expertise in heath record linkage. The Health Information Linkage Branch located at the Western Australian Department of Health undertakes core linkage of statewide Hospital Morbidity Data (HMD), Emergency Department Information System (EDIS) and the Death Register (DR) to which we are able to link ambulance service data. A full description of this linkage system has been previously published [14]. The 
Table 1. ICD 9 and ICD 10 Codes Used to Identify Disease Outcomes

\begin{tabular}{|c|c|c|}
\hline \multicolumn{3}{|c|}{$\underline{\text { Cardiovascular Disease }}$} \\
\hline \multirow[t]{7}{*}{ ICD9 } & Acute Myocardial Infarction & $410.0,1,2,3,4,5,6,7,8,9$ \\
\hline & Other acute and subacute forms & \\
\hline & of Ischaemic Heart Diseases & $411.0,1,8$ \\
\hline & Old Myocardial Infarction & 412 \\
\hline & Angina Pectoris & $413.0,1,9$ \\
\hline & Other forms of chronic & \\
\hline & Ischaemic Heart Diseases & $414.0,1,8,9$ \\
\hline \multirow[t]{7}{*}{ ICD10 } & Angina Pectoris & $\mathrm{I} 20.0,1,8,9$ \\
\hline & Acute Myocardial Infarction & I21.0,1,2,3,4,9 \\
\hline & Subsequent Myocardial Infarction & $\mathrm{I} 22.0,1,8,9$ \\
\hline & Certain current complications following & \\
\hline & Acute Myocardial Infarction & I23.0,1,2,3,4,5,6,8 \\
\hline & Other Ischaemic Heart Diseases & $\mathrm{I} 24.0,1,8,9$ \\
\hline & Chronic Ischaemic Heart Diseases & $\mathrm{I} 25.0,1,2,3,4,5,6,8,9$ \\
\hline \multicolumn{3}{|c|}{$\underline{\text { Cerebrovascular Disease }}$} \\
\hline \multirow[t]{6}{*}{ ICD9 } & Intracerebral Haemorrhage & 431 \\
\hline & Occlusion and stenosis of & \\
\hline & precerebral arteries & $433.0,1,2,3,8,9$ \\
\hline & Occlusion of cerebral arteries & $434.0,1,9$ \\
\hline & Acute, but ill-defined, & \\
\hline & Cerebrovascular Disease & 436 \\
\hline \multirow[t]{10}{*}{ ICD10 } & Cerebral Infarction & I63.0,1,2,3,4,5,6,8,9 \\
\hline & Stroke & I64 \\
\hline & Occlusion and stenosis of & \\
\hline & precerebral arteries, not resulting & \\
\hline & in Cerebral Infarction & I65.0,1,2,3,8,9 \\
\hline & Occlusion and stenosis of & \\
\hline & cerebral arteries, not resulting & \\
\hline & in Cerebral Infarction & $\mathrm{I} 66.0,1,2,3,4,8,9$ \\
\hline & Intracerebral Haemorrhage & \\
\hline & (haemorrhagic stroke) & I61.0,1,2,3,4,5,6,8,9 \\
\hline Diabetes & in Cerebral Infarction & \\
\hline ICD9 & Diabetes Mellitus & $250.0,1,2,3,4,5,6,7,8,9$ \\
\hline \multirow[t]{5}{*}{ ICD10 } & Impaired glucose regulation & E09.0,1,8,9 \\
\hline & Type 1 diabetes mellitus & E10.0,1,2,3,4,5,6,7 \\
\hline & Type 2 diabetes mellitus & E11.0,1,2,3,4,5,6,7 \\
\hline & Other specified diabetes mellitus & E13.0,1,2,3,4,5,6,7 \\
\hline & Unspecified diabetes mellitus & E14.0,1,2,3,4,5,6,7 \\
\hline
\end{tabular}


(Table 1). Contd.....

\begin{tabular}{|c|c|c|}
\hline \multicolumn{3}{|l|}{ Cancer } \\
\hline \multirow[t]{8}{*}{ ICD9 } & Malignant neoplasm of: & \\
\hline & -lip, oral cavity,and pharynx & 140-149 \\
\hline & -digestive organs and peritoneum & $150-159$ \\
\hline & -respiratory and intrathoracic organs 1 & $60-165$ \\
\hline & -bone, connective tissue, skin $\&$ breast & $170-175$ \\
\hline & -genitourinary organs & 179-189 \\
\hline & -other \& unspecified sites & 190-199 \\
\hline & -lymphatic \& haemopoietic tissue & $200-208$ \\
\hline \multirow[t]{4}{*}{ ICD10 } & Neoplasm & $\mathrm{C} 01-\mathrm{C} 96$ \\
\hline & In-situ Neoplasms & D00-D09 \\
\hline & Neoplasms of uncertain or & \\
\hline & unknown behaviour & D37-D48 \\
\hline \multicolumn{3}{|l|}{$\underline{\text { Renal }}$} \\
\hline \multirow[t]{8}{*}{ ICD9 } & Acute glomerulonephritis & $580.0,4,8,9$ \\
\hline & Nephrotic syndrome & $581.0,1,2,3,8,9$ \\
\hline & Chronic glomerulonephritis & $582.0,1,2,4,8,9$ \\
\hline & Nephritis and nephropathy, not & \\
\hline & specified as acute or chronic & $583.0,1,2,4,6,7,8,9$ \\
\hline & Acute renal failure & $584,584.5,6,7,8,9$ \\
\hline & Chronic renal failure \& impairment & $585,585.1,9$ \\
\hline & Renal failure, unspecified & 586 \\
\hline \multirow[t]{5}{*}{ ICD10 } & Hypertensive renal disease & I12 \\
\hline & Hypertensive heart \& renal disease & I13 \\
\hline & Glomerular disease & N00-N05 \\
\hline & Renal tubulo-interstitial diseases & N10-N12 \\
\hline & Renal failure & N17-N19 \\
\hline \multicolumn{3}{|c|}{ Liver Disease } \\
\hline \multirow[t]{5}{*}{ ICD9 } & Acute and subacute necrosis of liver & 570 \\
\hline & Chronic liver disease \& cirrhosis & $571.4,5,6,8,9$ \\
\hline & Liver abscess \& sequelae of & \\
\hline & Chronic liver disease & $572.0,1,2,3,4,8$ \\
\hline & Other disorders of liver & $573.0,3,4,8,9$ \\
\hline \multirow[t]{8}{*}{ ICD10 } & Toxic liver disease & K71.0,1,2,3,4,5,6,7,8,9 \\
\hline & Hepatic failure, & \\
\hline & not elsewhere classified & $\mathrm{K} 72.0,1,9$ \\
\hline & Chronic hepatitis, & \\
\hline & not elsewhere classified & $\mathrm{K} 73.0,1,2,8,9$ \\
\hline & Fibrosis \& cirrhosis of liver & K74.0,1,2,3,4,5,6 \\
\hline & Other inflammatory liver disease & $\mathrm{K} 75.0,1,2,3,4,8,9$ \\
\hline & Other diseases of liver & $\mathrm{K} 76.0,1,2,3,4,5,6,7,8,9$ \\
\hline
\end{tabular}


quality of the hospital morbidity data linkage has been assessed by a sampling technique to the percentage of invalid links (false positives) and missed links (false negatives) estimated to both be $0.11 \%$ [14].

The aim of this study was to use record linkage to compare the morbidity and mortality event rates in patients administered Methoxyflurane in the pre-hospital setting to a cohort of pre-hospital patients who did not receive Methoxyflurane.

\section{METHODS}

The Western Australian Ambulance Service provides $100 \%$ of all road based emergency ambulance services for WA covering approximately 2.5 million square kilometers. Patient, demographic, service and clinical details are recorded on the patient care record form (PCRF) for all occasions of service. This information is subsequently entered into a name identified by a computerised patient recording system.

A retrospective cohort of patients managed in the prehospital setting by the Western Australian Ambulance Service during 1990 to 2004, data was linked to the HMD, EDIS and DR data. Linkage keys were developed by using probabilistic matching of individual patients based on assigned weights to patient identifiers common in the master files. Questionable links were resolved through clerical checks of the data. These record linkage keys allowed for the creation of a unique patient record consisting of the information from each of the linked datasets. Analyses were then undertaken based on individual episodes of care or by individual patients (i.e. all episodes of care relating to that specific patient).

The cohort of patients receiving Methoxyflurane administration was identified through a specific code noted on PCRF, which is recorded in the ambulance service database. Index cases were determined as the first recorded prehospital episode, where the patient received Methoxyflurane. Where patients used an ambulance subsequent to the index event and Methoxyflurane was again administered, these events were summed to give an aggregated number of Methoxyflurane events over the study period. The non Methoxyflurane administered cohort consisted of all patients managed by the ambulance service but did not receive Methoxyflurane during the study period.

Methoxyflurane $(0.3 \%)$ is administered under a clinical practice guideline allowing for $3 \mathrm{mls}$ via inhaler to be given which may be repeated once. It was not possible to determine the exact dose administered during any one episode.

A composite outcome of either hospital admission or death was used as the primary endpoint. These were identified from the ICD9 or ICD10 diagnostic code relating to either "any ischaemic heart disease", "any diabetes", "any cancer", "any renal disease" or "any hepatic" disease recorded in either the HMD and /or DR. Where multiple diseases were recorded for a patient, these were included as separate occurrences. Table 1 outlines the ICD9 and ICD10 codes used in the study.

The cohort consisted of all patients transported by ambulance to hospital between 1990 and 2000 with follow-up period extending to the $31^{\text {st }}$ December 2004. This was al- lowed for a minimum of 4 years and a maximum of 14 years of follow-up.

Univariate and descriptive analysis was undertaken to describe the cohort. Crude and age standardized event rates were calculated for the primary outcome for the Methoxyflurane and non Methoxyflurane groups. Denominators for age strata were obtained from the Australian Bureau of Statistics and standardisation was calculated by using direct method. Logistic regression was used to calculate the odd ratios for each outcome of interest. In each of the models developed age and gender were included as these were considered potential confounders for outcome, with $95 \%$ confidence intervals derived for each of the estimates. Analysis was undertaken by using SPSS version 15. Ethics approval for the study was granted by the Human Research Ethics Committees at the University of Western Australia and Health Department of Western Australia.

\section{RESULTS}

The cohort comprised 135,770 patients of which 17,629 $(13 \%)$ received at least one dose of Methoxyflurane. The average age in the Methoxyflurane group was 45.8 years (Median 42.0 years; Range 1 - 104 years) compared to 43.4 (Median 42.0 years; Range $1-102$ years) in the non Methoxyflurane group. Males accounted for $48.9 \%$ and $51.1 \%$ of the Methoxyflurane and non-Methoxyflurane groups, respectively.

Among 17,629 patients who received Methoxyflurane, $14,410(81.7 \%)$ patients received Methoxyflurane on a single occasion. $1,575(8.9 \%)$ received Methoxyflurane on two separate occasions with a further 341 (2.0\%) receiving Methoxyflurane on 3 separate occasions. Only one patient received Methoxyflurane on 27 separate occasions.

Trauma was the primary indication for the use of Methoxyflurane in $9,755(55.3 \%)$ cases with acute abdominal pain 2, $207(12.5 \%)$, inflammatory musculoskeletal $2,109(12.0 \%)$, cardiac $479(2.7 \%)$ and renal colic 247 $(1.4 \%)$ cases. These five conditions comprised a total of $83.9 \%$ of all Methoxyflurane administrations.

In patients administered Methoxyflurane, no increased risk was observed in any of the disease groups under investigation when compared with pre-hospital care patients who were not administered Methoxyflurane. In addition the time taken for the first occurrence of disease to occur was similar to the Methoxyflurane and non Methoxyflurane groups. These results are further described in Table 2. Furthermore, we observed no increased risk of disease occurrence in the Methoxyflurane group for each individual ICD code within each of the five disease categories investigated.

Additional analysis was undertaken on a subgroup of cases comprising children aged less than or equal to 12 years of age. This sub-cohort comprised 14,753 patients of which only $594(4 \%)$ received Methoxyflurane. As with the over 12 years of age cohort no increased risk of disease was observed (Table 3).

\section{DISCUSSION}

Within the Western Australia, Methoxyflurane has been used by the ambulance service as an analgesic agent for over two decades. It is patient self administered via an inhaler and 
Table 2. Outcomes by Disease Group for Patients Receiving and Not Receiving Methoxyflurane Pre-Hospital

\begin{tabular}{|c|c|c|c|c|c|}
\hline & $\begin{array}{l}\text { Ischaemic Heart } \\
\text { Disease }\end{array}$ & Diabetes & $\begin{array}{c}\text { Renal } \\
\text { Disease }\end{array}$ & Cancer & $\begin{array}{l}\text { Hepatic } \\
\text { Disease }\end{array}$ \\
\hline $\begin{array}{c}\text { All events n } \\
\text { Received Methoxyflurane }\end{array}$ & 25688 & 16476 & 12445 & 24065 & 2718 \\
\hline $\mathrm{N}(\%)$ & $2271(8.8)$ & $1916(11.6)$ & $1596(12.8)$ & $2898(12.0)$ & $373(13.7)$ \\
\hline $\begin{array}{c}\text { Number of administrations } \\
\text { Mean (median; range) }\end{array}$ & $1.3(1.0 ; 1-24)$ & $1.3(1.0 ; 1-19)$ & $1.3(1.0 ; 1-11)$ & $1.3(1.0 ; 1-12)$ & $1.6(1.0 ; 1-27)$ \\
\hline $\begin{array}{l}\text { Time to onset of event (yrs) } \\
\text { Mean (median) }\end{array}$ & $2.8(1.8)$ & $2.7(1.4)$ & $4.1(3.7)$ & $4.0(3.4)$ & $3.9(3.5)$ \\
\hline $\begin{array}{l}\text { Age standardised event rate (per } \\
\qquad 1,000 \text { patients) }\end{array}$ & 1.21 & 1.11 & 0.93 & 1.59 & 0.22 \\
\hline \multicolumn{6}{|l|}{ No Methoxyflurane } \\
\hline $\mathrm{N}$ & 23417 & 14560 & 10849 & 21167 & 2345 \\
\hline Age Mean (Median) & $67.0(69.0)$ & $60.7(64.0)$ & $65.7(71.0)$ & $66.4(70.0)$ & $55.8(57.0)$ \\
\hline Male n (\%) & $12927(55.2)$ & 7407 (50.9) & $5603(51.6)$ & $11172(58.2)$ & $1291(54.8)$ \\
\hline $\begin{array}{l}\text { Time to onset of event (yrs) } \\
\text { Mean (median) }\end{array}$ & $3.2(1.9)$ & $3.7(2.6)$ & $5.8(5.5)$ & $5.2(4.7)$ & $5.1(4.4)$ \\
\hline
\end{tabular}

Table 3. Outcomes by Disease Group for Paediatric Patients Receiving and Not Receiving Methoxyflurane Pre-Hospital

\begin{tabular}{|c|c|c|c|c|c|}
\hline & IHD & Diabetic & Renal & Cancer & Hepatic \\
\hline $\mathrm{N}$ & 1 & 6 & 2 & 3 & 2 \\
\hline $\begin{array}{l}\text { Crude event rate } \\
\text { (per 1,000 patients) }\end{array}$ & 1.6 & 10.1 & 3.3 & 5.0 & 3.3 \\
\hline $\mathrm{N}$ & 14 & 153 & 141 & 134 & 28 \\
\hline $\begin{array}{l}\text { Crude event rate } \\
\text { (per } 1,000 \text { patients) }\end{array}$ & 0.9 & 10.8 & 9.9 & 9.4 & 1.9 \\
\hline
\end{tabular}


indicated for the temporary emergency management of acute pain in the pre-hospital setting. There have been a small number of published studies describing the efficacy, effectiveness and safety of this agent. The limited data available indicates that Methoxyflurane is an effective analgesia; however an adverse association between the occurrence of hepatitis and renal disease in patients being administered or by using Methoxyflurane has been reported. In each of these reports, Methoxyflurane was used in higher concentrations and / or for extend period of time than what is used by the ambulance service as a pre-hospital analgesic.

This population-based study used routinely collected linked administrative data to assemble a large cohort of patients over a 14 year period. The patients followed-up for at least 4 years and to a maximum of 14 years. The cohort consisted of 135,770 cases with 17,629 (13\%) receiving Methoxyflurane.

The sex and age characteristics were generally similar in each of the disease groups for both Methoxyflurane and nonMethoxyflurane patients. In this study, over $80 \%$ of the patients who received Methoxyflurane received this agent on a single occasion. It was observed that the time to event was generally similar between the two groups; however, a trend towards a shorter period in the Methoxyflurane group compared to the non-Methoxyflurane group was noted. This may be due to the underlying nature and severity of the disease in patients with more advanced disease states and requiring analgesia.

In each of the five disease conditions investigated the crude and age adjusted event rates were similar in the Methoxyflurane group compared with the non Methoxyflurane group. Odds ratios for the occurrence of disease or death from disease in those who received Methoxyflurane compared to those who were non significant with the $95 \%$ confidence limits including an odd ratio of 1.0. These findings remained similar for both the whole cohort and in the cohort of children aged 12 years or less.

This is the first study, which has attempted to establish whether long-term health may occur in patients administered Methoxyflurane. The study has not identified any increase in the risk of disease occurrence or death with the use of Methoxyflurane to that of a similarly comparable group.

The findings of this study are at odds with the previously published reports of adverse health outcomes, leading to death in some cases. It is important when considering these findings where adverse health events that occurred, Methoxyflurane was used in both higher concentrations and over a longer period of time in order to manage acute pain in these patients. Similarly, the cumulative effects of Methoxyflurane producing toxicity after prolonged exposure may explain such findings. In the Western Australian Ambulance Service, the exposure to Methoxyflurane was predominantly a one off event, of a lower concentration and given over a relatively short duration of usually less than 45 minutes.

Despite this being, a large population based study, a number of limitations associated with the use of administrative data should be highlighted. We were not able to ascertain the accuracy / validity of the data for each database used. However, previously published validation studies of clinical cohorts assembled through administrative databases have indentified error rates of less than 5\%. Similarly, the influence of any data inaccuracies contained in this clinical cohort of ambulance patients - receiving or not receiving Methoxyflurane - is likely to have minimal effect on the outcomes observed. In addition, we were not able to include those patients who may have developed the disease under investigation but were not admitted to hospital or died. However the likelihood of patients developing such diseases and not having at least one hospital admission (particularly in the Western Australia) would be very low and thus would have minimal impact on our findings.

A further limitation of this study is that we were not able to assess the actual dose of Methoxyflurane administered to patients during the course of their pre-hospital care. Similarly, we are not able to determine or model a dose - response relationship for individual patients receiving Methoxyflurane. Finally this study focussed on the exposure of patients to mostly one off or very infrequent doses of Methoxyflurane. The health effects associated with occupational exposure of Paramedics to Methoxyflurane could not be assessed and may have a different risk profile.

Notwithstanding the above, this study suggests that there is no evidence, that the use of Methoxyflurane in the prehospital setting as currently recommended, is associated with an increased likelihood of the Ischaemic Heart Disease, Diabetes, Cancer, Renal or Hepatic disease in patient's receiving this agent.

\section{ACKNOWLEDGEMENT}

The author thanks Associate Professor Nick Gibson and Bekah Andrews for their assistance with data extraction and reviewing the manuscript.

\section{CONFLICTS OF INTEREST}

Medical Developments Australia (MDA) are the Australian manufactures of Methoxyflurane and provided funding to undertake this study. MDA had no input into the design, analysis, interpretation of results or preparation of this manuscript for publication.

\section{REFERENCES}

1] Yakaitis RW, Cooke JE, Redding JS. Self-administered methoxyflurane for postoperative pain: effectiveness and patient acceptance. Anesth Analg 1972; 51(2): 208-12.

[2] Rosen M, Mushin WW, Jones PL, Jones EV. Methoxyflurane for obstetric analgesia. Br Med J 1969; 4(5680): 432-3.

[3] Packer KJ, Titel JH. Methoxyflurane analgesia for burns dressings: experience with the analgizer. Br J Anaesth 1969; 41(12): 1080-5.

[4] Knox PR, North WC, Stephen CR. Methoxyflurane--a clinical evaluation. Anesthesiology 1962; 23: 238-42.

[5] Thomason R, Light G, Holaday DA. Methoxyflurane anesthesia: a clinical appraisal. Anesth Analg 1962; 41: 225-9.

[6] Artusio JF, Van Poznak A, Hunt RE, Tiers RM, Alexander M. A clinical evaluation of methoxyflurane in man. Anesthesiology 1960; 21: 512-7.

[7] Babl F, Barnett P, Palmer G, Oakley E, Davidson A. A pilot study of inhaled methoxyflurane for procedural analgesia in children. Paediatr Anaesth 2007; 17(2): 148-53.

[8] Babl FE, Jamison SR, Spicer M, Bernard S. Inhaled methoxyflurane as a prehospital analgesic in children. Emerg Med Australas 2006; 18(4): 404-10.

[9] Toomath RJ, Morrison RB. Renal failure following methoxyflurane analgesia. N Z Med J 1987; 100(836): 707-8.

[10] Delia JE, Maxson WS, Breen JL. Methoxyflurane hepatitis: two cases following obstetric analgesia. Int J Gynaecol Obstet 1983 ; 21(1): 89-93. 
[11] Dahlgren BE. Fluoride concentrations in urine of delivery ward personnel following exposure to low concentrations of methoxyflurane. J Occup Med 1979; 21(9): 624-6.

[12] Dahlgren BE. Urinary fluoride concentration in mothers and neonates after methoxyflurane-nitrous oxide analgesia during labour. Acta Pharm Suec 1978; 15(3): 211-7.

[13] Cuasay OS, Ramamurthy R, Salem MR, Sendaydiego PM, Elgindy LI, Caburnay FS. Inorganic fluoride levels in parturients and neo- nates following methoxyflurane analgesia during labor and delivery. Anesth Analg 1977; 56(5): 646-9.

[14] Sprivulis P, Jacobs I, DaSilva J, Jelinek G, Swift R. The Western Australian Emergency Care Hospitalisation and Outcome Linked Data Project. Aust NZJ Pub Health 2006; 30: 123-7.

(C) Ian G. Jacobs; Licensee Bentham Open .

This is an open access article licensed under the terms of the Creative Commons Attribution Non-Commercial License (http://creativecommons.org/licenses/by-nc/3.0/) which permits unrestricted, non-commercial use, distribution and reproduction in any medium, provided the work is properly cited. 